Higgins, G.E., Wolfe, S.E., \& Marcum, C.D. (2008). Digital piracy: An examination of three measurements of selfcontrol. Deviant Behavior, 29(5): 440-461. Published by Taylor \& Francis (ISSN: 1521-0456).

DOI:10.1080/01639620701598023

\title{
Digital Piracy: An Examination of Three Measurements of Self-Control
}

George E. Higgins, Scott E. Wolfe, \& Catherine D. Marcum

\begin{abstract}
Research has shown a link between digital piracy and self-control. However, the research focuses on only one version of self-control theory. The purpose of the present study is to examine the link between self-control and digital piracy. Using data from 358 college students, this study shows that all 3 measures of self-control help us understand the link between selfcontrol and digital piracy. The results indicate that illuminating the factors that could be inhibitions and developing strong social bonds can reduce the likelihood of digital piracy.
\end{abstract}


Adler and Adler (2006) argued that the dramatic growth of the Internet has provided a haven for deviance and crime. For instance, individuals are able to find, copy, and use intellectual property without providing payment (i.e., pirate intellectual property). One form of intellectual property piracy that is increasing is digital piracy. Digital piracy is defined as the illegal act of copying digital goods, software, digital documents, digital audio (including music and voice), and digital video for any reason other than to backup without explicit permission from and compensation to the copyright holder (Gopal et al. 2004; Higgins et al. 2006). The Internet has facilitated an increase in digital piracy in recent years. Wall (2005) argued that the Internet enables individuals to easily commit criminal activity for four reasons: it allows anonymous communication, it is transnational, it has created a shift in thinking from the ownership of physical property to the ownership of ideas, and it is relatively easy. Additionally, Wall (2005) contends that the Internet facilitates piracy because it allows the offense to take place away from the copyright holder, which provides the offender with the perception that the act is victimless. However, this behavior is not a victimless behavior.

Digital piracy_especially music piracy_is increasing. The International Federation of Phonographic Industries (IFPI) (2006) estimated that almost 20 billion songs were illegally downloaded in 2005. The IFPI (2006) concluded that pirate CD sales outnumbered legitimate $C D$ sales in 30 markets across the world, resulting in a loss of 4.5 billion dollars from the music industry.

In the United States, intellectual property that includes digital media is protected by copyright laws. The illegal copying and distribution of copyrighted materials over the Internet was made a felony offense by The No Electronic Theft Act (Im and Koen 1990). These pieces of legislation are instrumental in making digital piracy a crime. Research on this topic is growing. Some researchers have used criminological theories to gain an understanding of digital piracy. To that end, some researchers have used self-control theory to examine digital piracy. To date, these researchers have focused on one form of self-control measures (i.e., personality) in their studies. However, in the literature, others (Hirschi 2004; Piquero and Bouffard 2007) have proposed different ways to measure self-control (i.e., as social bonds and self-generated inhibitions). These other measurements of self-control provide different insights into the connection between self-control and deviant behavior (i.e., digital piracy). Therefore, a gap is left in understanding the link between self-control and digital piracy in the literature.

The purpose of the present study is to fill the gap in understanding the link between self-control and digital piracy by testing three different measurements of self-control. Thus, the present study is important for two reasons. First, this study will assist in providing a unique understanding of the link between self-control and digital piracy because it will illuminate the different meanings of the connections between these two measures. Second, this study will provide information that may be used to develop policy to reduce instances of digital piracy. 


\section{SELF-CONTROL THEORY}

Gottfredson and Hirschi's (1990) version of self-control theory provides an important view of crime and deviance. They emphasize that the stable individual difference of low self-control provides a causal structure underlying deviance. To explain the stability of crime over time and the lack of specialization of crime, Gottfredson and Hirschi (1990) argued that crime is the result of low self-control. They argued that low self-control was, "the tendency to avoid acts whose long-term costs exceed their momentary advantages" (Hirschi and Gottfredson, 1994:3). Individuals with low self-control were characterized with the same characteristics of crime as: risk-taking, impulsive, lacks empathy, prefers simple and easy tasks, and prefers physical tasks. These characteristics inhibit an individual's ability to accurately calculate the consequences of deviance. In this form, low self-control explains all forms of crime-acts of force or fraud that individuals pursue in their own interest-and analogous acts. Further, low self-control originates in early socialization when parents are ineffective or inconsistent in their application of the parenting tasks. Therefore, neglecting, uncaring, and single parents are likely to fail to socialize their child to properly delay gratification, care about the feelings and desires of others, and properly control their impulses (i.e., exercise high level of self-control).

Although under scrutiny from several researchers, Gottfredson and Hirschi's theory has generated a moderate amount of empirical support for criminal and deviant behaviors (Pratt and Cullen 2000). Nevertheless, while several studies have examined the effects of self-control on crime and deviance, one issue has consistently arisen in the literature. Researchers should be clear about how the measurement of self-control can influence the interpretation of the link between self-control and digital piracy. For instance, as in the Grasmick et al. (1993) tradition, when researchers treat self-control as a personality trait, they are focusing on the characteristics that Gottfredson and Hirschi presented to indicate those with low self-control. Focusing on these characteristics does not allow researchers to gain an appreciation of the process of self-control that may be at work during the decision making to perform a behavior such as digital piracy. The characteristics can be applied to digital piracy to help outline this issue. For instance, those with low self-control are likely not to wait to purchase a copy of the digital media. These individuals are not likely to care about the copyright agreement that is attached to the digital media or believe that no one is being harmed. Further, these individuals may be attracted to the thrill, ease, and simplicity of performing digital piracy. Thus, from the characteristics of low selfcontrol, those with low self-control should be likely to perform digital piracy. To date, the empirical research shows some support for this view (Higgins 2005; Higgins et al. 2006). Therefore, in the present study, it is expected that the personality view of self-control will have a link with digital piracy.

Alternative conceptualizations and measurements of self-control are important to the literature as well. One alternative conceptualization takes the focus away from the characteristics and moves researchers away from viewing self-control as a personality trait or a predisposition for crime. In Hirschi's (2004) view, the personality use of self-control is: (1) a search for the motives of crime and delinquency that are counter to their original theory; (2) is a use that shows little value in the explanation of crime; (3) does not provide an explanation of how self-control operates but intimates that an individual will become criminal because they are who they are; 
and (4) produces a measure that does not view more as better than less. Thus, Hirschi (2004) sees self-control not as a personality trait or predisposition for crime, but self-control is the tendency to consider the full range of potential costs (i.e., inhibitions) of a particular act. Under this view, self-control is a set of inhibitions that an individual carries with them wherever they go. This removes the focus from long-term costs, and it allows any set of costs to be inhibitors while placing an emphasis on the contemporaneous nature of the inhibitions. That is, individuals are consistently considering the inhibitions for a behavior while in a situation. Thus, crime and delinquent acts are possible due to the absence of an enduring tendency to avoid them (i.e., the inability to see the full range of the inhibitions). Typical inhibitions that an individual considers are consonant with the bonds from social control theory (i.e., commitment, involvement, belief, and attachment) that provide a target for dishonor if a transgression is perpetrated. Because an individual becomes criminal or delinquent when they feel relatively free from intimate attachments, aspirations, and moral beliefs, a noncriminal or nondeviant individual is exercising self-control by recognizing and adhering to inhibitions so not to dishonor those that are admired. Therefore, self-control is akin to a self-imposed physical restraint on behavior.

To test this view, Hirschi (2004) used data from the Richmond Youth Survey. To capture the new conceptualization, he used nine items that capture a variety of social bonds (i.e., attachment, commitment, and belief). [1] He showed that his conceptualization of self-control has a negative link with delinquency. This is supportive of the reconceptualization of self-control that individuals add up the negative costs of an act and behave in accord. The important issue with this study was Hirschi's (2004) measures. His use of nine items that reflect social bonds is consistent with his view that self-control and social control are one in the same.

Piquero and Bouffard (2007) used data from college students to examine the reconceptualization of self-control. They interpreted Hirschi (2004) to be more from the rational choice tradition rather than the social bonding tradition. Their approach to operationalizing selfcontrol was to ask students to provide a list of seven "bad things" and the percentage of the likelihood of these "bad things" occurring. The product of these responses was added together and higher scores on the measure indicated more inhibitions. Piquero and Bouffard (2007) also included the Grasmick et al. (1993) measure. In comparison, the "bad things" measure of selfcontrol has a stronger link with drunk driving and sexual aggression than the Grasmick et al. scale.

These two studies show that Hirschi's (2004) conceptualization of self-control may have import for criminology. This view can be applied to digital piracy. That is, individuals are likely to perform digital piracy when they feel relatively free of their attachments, their aspirations, and moral beliefs. To that end, when an individual feels that they are anonymous using the Internet and that they are not likely to be detected performing digital piracy by someone that they admire or that digital piracy is immoral, they are likely to perform the behavior. Further, some may aspire to perform digital piracy because obtaining the digital media may provide a source of relaxation that is desirable. Thus, there is not any self-restraint from performing digital piracy. The present study assumes that the way Piquero and Bouffard (2007) used inhibitions and Hirschi (2004) used social bonds to capture self-control will have negative links with digital piracy. 


\section{THE PRESENT STUDY}

Research suggests that self-control has a link with digital piracy (Higgins 2005, 2006; Higgins and Makin 2004). Recognizing that multiple ways are present in the literature to measure selfcontrol that has different interpretations, the present study examines the links that self-control has with digital piracy using the Grasmick et al. (1993) measure, a social bonding measure similar to Hirschi (2004), and an inhibition measure similar to Piquero and Bouffard (2007).

The present study presents the first systematic study of the link between self-control and digital piracy using multiple measures of self-control and can be seen as contributing to the literature on Gottfredson and Hirschi's (1990) theory and Hirschi's (2004) revision. Regarding the study of digital piracy, this is the first systematic study to our knowledge that examines the link between these multiple measures of self-control and digital piracy. In addition, the present study may provide information that may allow for policy to be developed to reduce instances of the behavior.

\section{METHODS}

This section discusses the present study's sampling, procedures, and measures.

\section{Procedures and Sampling}

This study used a self-report questionnaire administered to college students at three universities in the southeastern United States. Upon Institutional Review Board and Human Subject Protection review, data were collected during the 2006 fall semester. The survey was handed out to required general education courses open to all majors and courses only open to justice administration majors. Professors of the surveyed classes had given prior permission for the study to take place during class. Students present in class on the day that the questionnaire was administered took part in the study. A cover letter explained the purpose of the study, the voluntary nature of the study, and that responses would be completely anonymous and confidential. The researchers also verbally stressed these rights to the students as the survey was being handed out. Following these procedures, approximately 358 surveys were collected as part of the sample with 10 individuals refusing to participate.

Some may criticize the use of a college student sample because of its lack of generalizability. Self-control theory is a general theory that has been thought to explain all crime all of the time, no matter the sample. Consequently, issues of generalizability are minimized in the present study (Higgins 2005).

However, the research shows that college students, as a group, are the most likely to engage in digital piracy (Higgins et al. 2006; Hinduja 2003; Hollinger 1988; Husted 2000). College students have regular access to computers, are seen as less grounded in ethical standards, and are less controlled by vigorous rule enforcement on campuses (Hinduja 2003). Additionally, college students are more likely to engage in digital piracy due to insufficient financial funds to acquire 
digital media through legitimate means. Therefore, the current study has sampled those individuals most likely to engage in digital piracy, college students.

\section{Measures \\ Dependent Measure}

Consistent with previous research on digital piracy (Higgins et al. 2006; Piquero and Bouffard 2007; Piquero and Tibbetts 1996), the dependent measure in the present study was the response to a single item attached to a hypothetical scenario. The item is, "I would go to the web-site with the intention to download the CD under these circumstances." Respondents marked their level of likelihood to perform the behavior on an 11-point scale that ranged from not likely (0) to 100\% intention (10). The scores ranged from 0 to 10 . An individual's intention of performing the act was indicated by higher scores reflecting greater intentions.

\section{Low Self-Control}

The present study used a 24-item composite scale from Grasmick et al. (1993) to capture the personality version of low self-control. Respondents answers could range from $1=$ strongly disagree to $4=$ strongly agree. The score on the scale ranged from 24 to 96 . Factor analysis indicated that this measure could be considered as a single factor (Note: the results are available on request from the first author). For this study, the measure will be treated as a unidimensional measure that is consistent with previous research (Grasmick et al. 1993; Piquero and Bouffard 2007; Tittle et al. 2003). This use of the items is consistent with Hirschi's (2004) view that the unidimensional trait that the items can form is just as predictive as the six subscales that the items may produce. Further, Cronbach's alpha indicates proper levels of internal consistency (.88). Higher scores on the scale indicated lower levels of self-control.

\section{Self-Generated Inhibitions}

Some researchers have contended that the used of hypothetical scenarios may not accurately reflect a person's real-world decision-making process, because they are artificially articulated by the researcher (Bouffard, 2002). In particular, Bouffard (2002) argued that the use of hypothetical scenarios may lead to priming of the respondents' answers and create methodological problems. To remedy these problems, Piquero and Bouffard (2007) suggested the use of subject-generated consequences to measure self-control. The present study has utilized this contemporary view of self-control using this methodology by presenting respondents with a table in order for them to develop their own measures of deterrence.

For the scenario (going to the website to download the $\mathrm{CD}$ ) respondents were asked to list five "bad things" that might occur if one were to engage in the act and, then on the corresponding side of the table, to indicate the importance (0 to 100\%) of each of the "bad things" when they 
make the decision to perform the act. Individuals with longer lists are viewed to have taken more time to think about the potential cots of a behavior, whereas those with low self-control ignore the long-term costs of the behavior that is consistent with Gottfredson and Hirschi's (1990) contention. As a result, the respondents' self-generated responses will not only be used to gauge the individual's level of self-control. According to Piquero and Bouffard (2007), the use of self-generated responses will better capture an individual's true inhibitions and more accurately capture self-control. Factor analysis using a varimax rotation and scree test indicated that these inhibitions formed a unidimensional measure with adequate levels of internal consistency (.70) (Note: the results are available on request from the first author).

\section{Bonding Self-Control}

Similar to Piquero and Bouffard (2007), a measure of social bonding is included in this study. However, this study uses bonding as a measure of self-control to be consistent with Hirschi (2004). Hirschi (2004) suggested that the more bonded an individual was then the more inhibitions were in the individual's life. Seven items capture commitment to school and attachment to parents. The students responded to the items using the answer choices "1—not important" to "5-very important." Factor analysis using a varimax rotation and a scree test indicates that this measure forms a unidimensional measure (Note: the results are available on request from the first author). Further, this measure has proper levels of internal consistency (.82). The scores ranged from 7 to 35 . Higher scores on the scale indicate stronger bonding or more inhibitions.

\section{Associating with Peers}

Whereas Hirschi (2004) argued that associating with delinquent or criminal peers is a form of inhibitions, the present study uses the measure to account for differential association in the context of Akers's (1998) theory. Consistent with previous research (Higgins et al. 2006), the present study used a measure that used six items to capture the students' perceptions of the number of male and female friends that download music. The students responded using the answer choices ( $1=$ none, $2=1-2,3=3-4,4=5$ or more). The scores ranged from 5 to 24 . Factor analysis using a varimax rotation and a scree test shows that the scale was unidimensional. Cronbach's alpha analysis indicates that the scale is internally consistent (.95).

\section{Additional Control Measures}

The respondents were asked their age (an open-ended question), sex ( $1=$ male, $0=$ female), and race $(0=$ non-white, $1=$ white). Consistent with Higgins et al. (2006), additional control measures were obtained by asking the respondents how many times in the past 2 weeks they downloaded music without paying ( $1=$ zero times, $2=1-2$ times, $3=3-4$ times, and $5=$ more than 5 times). 


\section{RESULTS}

Table 1 presents the means, standard deviations, and bivariate correlations for the present study. Forty percent of the respondents indicate they are likely to download the music as described in the scenario. Diagnostics of this measure did not indicate an overly skewed or kurtotic distribution of this measure. The average student downloaded nearly two times in the past two weeks. The average Grasmick et al. scale score indicated moderate levels of low selfcontrol. The average bonding self-control scale indicates high levels of self-control. The average score of the Piquero and Bouffard measure indicates low levels of self-control. These findings indicate some disjuncture in the self-control measures. That is, these interpretations indicate different directions in self-control levels. However, these interpretations are consistent with the interpretations that were used to develop the measures. For instance, Grasmick et al. developed their measures under the guise that less self-control was to be captured. However, Piquero and Bouffard's self-generated inhibitions measure and the social bonding measure were developed under the guise that more was better. The students average moderate levels of association with downloading peers. The average sex in the sample is females that were around 21 years old. 


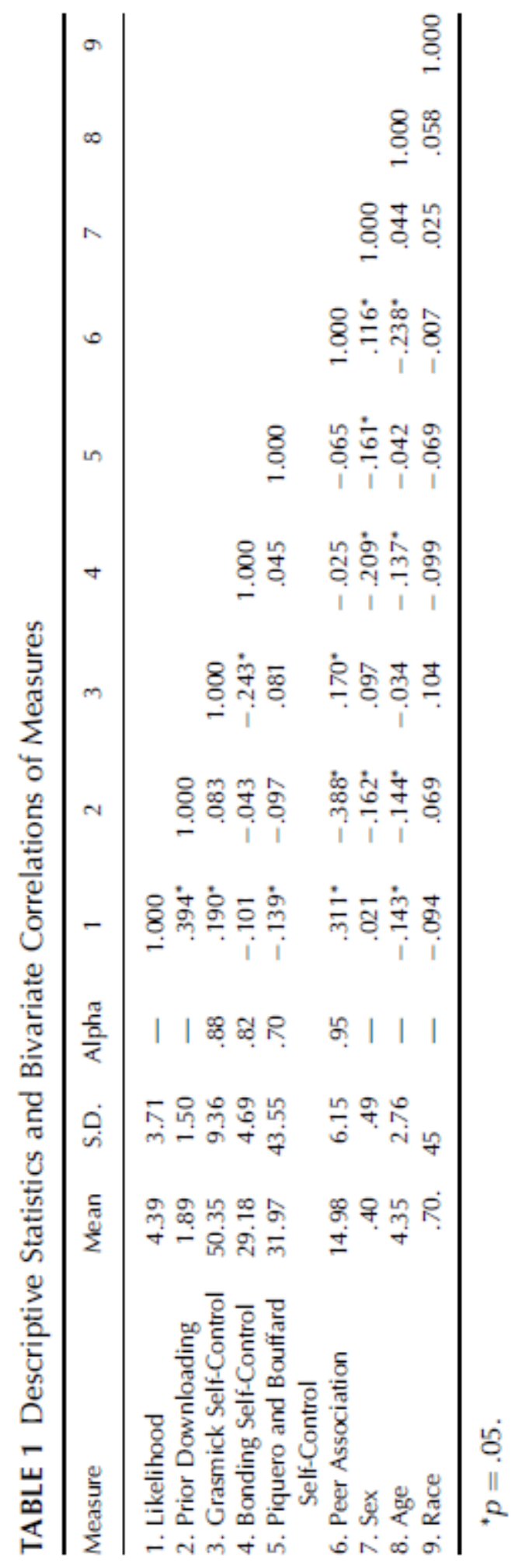


The bivariate correlations indicate that all of the measures have desired effects on the likelihood of downloading music except the bonding self-control measure. For instance, prior downloading has a link with the likelihood $(r=.394)$. Grasmick et al. (1993) has a link with the likelihood of downloading music $(r=.190)$ that is consistent with Higgins et al. (2006). The bonding selfcontrol measure does not have a link with downloading music $(r=-.101)$ that is not consistent with Hirschi (2004). Consistent with Piquero and Bouffard (2007) their measure of self-control has a link with the likelihood of downloading music $(r=-.139)$. Further, associating with downloading peers has a link with downloading music $(r=.311)$ that is consistent with the predictions from Akers (1998). Further, the largest correlation among the measures is .394 indicating that multicollinearity is not a problem with these data, but further tests of multicollinearity will be performed in the regression analysis.

Table 2 presents the regression analysis that uses downloading music as the dependent measure. The three operational definitions of self-control are entered separately to determine their independent feasibility in understanding digital piracy. Finally, the three operational definitions of self-control are entered simultaneously to determine if one measure can reduce the others to nonsignificance, thus shedding light on the measure that may be more productive in understanding digital piracy. 


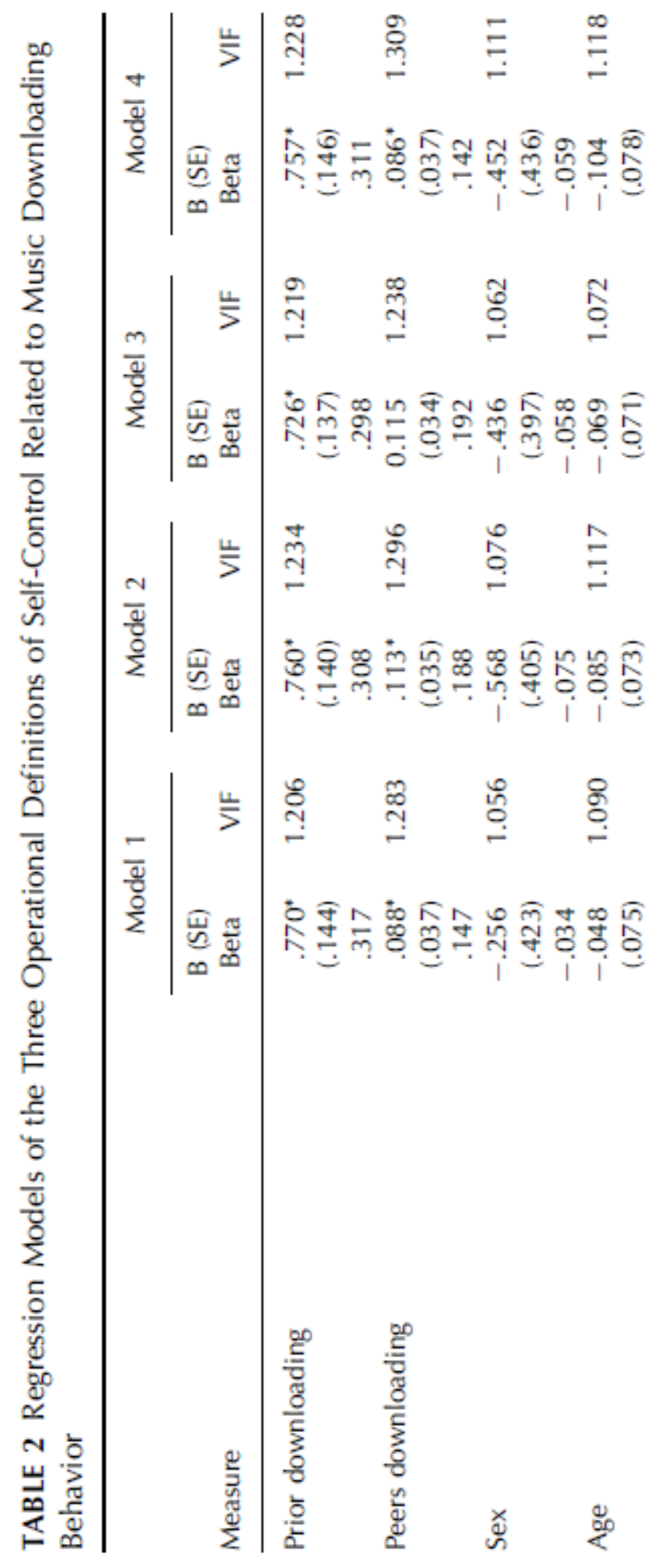




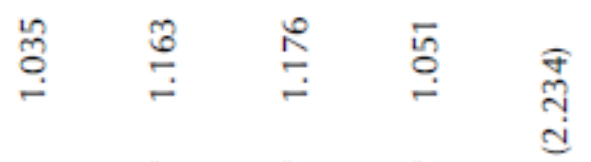

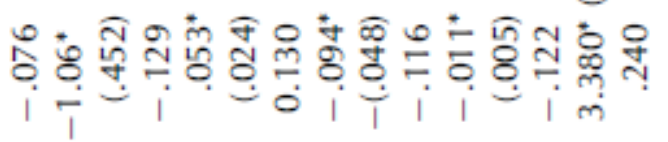

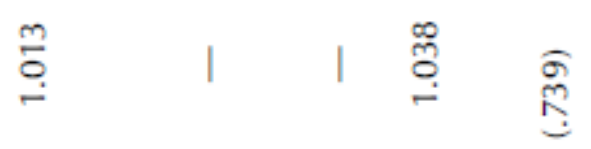

Вํํำ

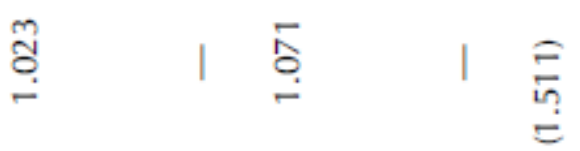

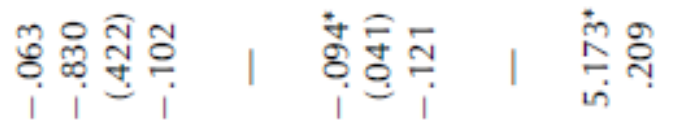

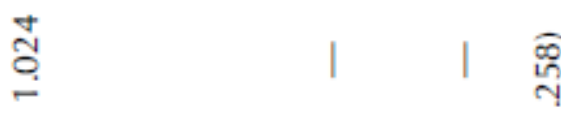

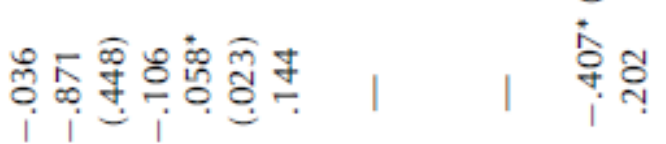

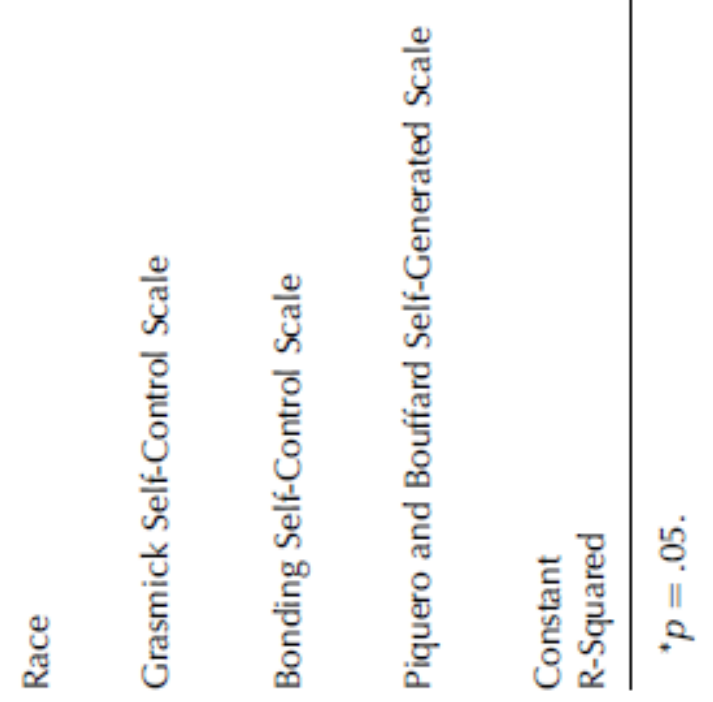


In Table 2, model 1 shows the results of a regression model that contains the Grasmick et al. self-control measure. The results show that prior downloading $(b=.770, B=.317)$, downloading peers $(b=.088, B=.147)$, and Grasmick et al. $(1993)$ scale $(b=.058, B=.144)$ are significant in understanding digital piracy. Associating with downloading peers indicates support for Akers's (1998) view that differential association is an important measure in understanding criminal behavior. In this study, the behavior is digital piracy. The results of model 1 indicate support for the personality view of self-control theory. That is, individuals that exhibit the likelihood of downloading music do so because they are impulsive, risk-taking, and prefer simple and easy activities.

Multicollinearity is examined in all of these regression models using the variance inflation factor (VIF). Field (2000) indicates that a VIF below 4.00 indicates that multicollinearity is not present in the data. All of the VIF coefficients across model 1 are below 2 indicating that multicollinearity is not a problem in this model.

Model 2 presents results of a regression model that contains the bonding self-control measure. The results are consistent with model with respect to prior downloading $(b=.760, B=.308)$ and associating with downloading peers $(\mathrm{b}=.113, \mathrm{~B}=.188)$. However, model 2 indicates that the bonding measure of self-control is statistically relevant $(b=-.094, B=-.121)$. This result supports Hirschi's (2004) results. Importantly, the result indicates that individuals that have more inhibitions are less likely to download music. This means that individuals who do not perceive themselves as being free from intimate attachments with parents and commitments to school are likely to download music. Importantly, the VIF coefficients indicate that multicollinearity is not a problem in these data because they are all below 2.00 .

Model 3 presents the results of the model containing the Piquero and Boffard (2007) selfgenerated inhibitions scale. The results are similar to models 1 and 2 in the context of prior downloading $(b=.726, B=.298)$ and associating with downloading peers $(b=.115, B=.192)$. The results indicate that the Piquero and Bouffard (2007) measure of self-control has a negative link with the likelihood to download music $(b=-.011, B=-.132)$. This result suggests that the more inhibitions the individuals were able to list the less likely that the individuals were to indicate that they were likely to download music, supporting Hirschi (2004). Thus, the less free the individual perceives themselves the less likely the individual is to download music. Further, the VIF coefficients are below 2.00 indicating that multicollinearity is not a problem with these data.

Model 4 shows the results of a regression model that includes all three of the self-control theory measures. This model continues to show that prior downloading $(b=.757, B=.311)$ and associating with downloading peers $(b=.086, B=.142)$ have a link with the likelihood of downloading music. Specifically, the Piquero and Bouffard (2007) measure has a link with the likelihood of downloading music $(b=-.011, B=-.122)$. The Grasmick et al. measure of selfcontrol has a link with the likelihood of downloading music $(b=.053, B=.130)$. The bonding self-control measure has a link with the likelihood of downloading music $(b=-.094, B=-.116)$. The results show that all three measures of self-control are statistically significant. Thus, in these data, none of the measures of self-control explain so much more variance than the other 
measures of self-control to drive them to nonsignificance. Therefore, these data support all of the versions of self-control theory. [2,3] Further, the VIF coefficients do not indicate that multicollinearity is a problem with these measures.

\section{DISCUSSION}

The purpose of the present study was to provide an understanding of digital piracy by examining three different approaches of self-control. Specifically, the present study examined whether a personality measure of self-control (i.e., Grasmick et al. 1993), social bonding (Hirschi 2004), and self-generated inhibitions (Piquero and Bouffard 2007) had links to digital piracy. These three different measures provide two different interpretations that provide important understandings of digital piracy. To examine these issues, a survey was given to 358 undergraduate students with a hypothetical scenario of illegally downloading music from the Internet (i.e., digital piracy).

The results from this study offer some insight into digital piracy through self-control theory. First, the results indicate that an individual is likely to perform digital piracy because of who they are as indicated by the characteristics of low self-control that Gottfredson and Hirschi (1990) presented. Specifically, the positive results from Grasmick et al. (1993) indicated that an individual is likely to perform digital piracy because they are impulsive and unable to wait to purchase a copy of the digital media. These individuals are not likely to be empathetic to the potential copyright holder and perform the behavior. Further, these individuals are likely to be attracted to ease and simplicity of performing digital piracy. This result is consistent with the previous literature that has examined the connection between low self-control and digital piracy (Higgins 2005, 2006; Higgins and Makin 2004). Overall, this result indicates that the personality characteristics have a link with digital piracy, but it gives the impression that low self-control is a positive force that will motivate individuals to perform digital piracy. This may not be construed as being consistent with Gottfredson and Hirschi's view that the tendency to commit crime is probabilistic and not deterministic. It may be seen as a positive or motivating force from performing digital piracy. At this point, it should be noted that this is not an admonishment of the Grasmick et al. scale or the use of it, but merely an attempt to point out how misinterpretations of Gottfredson and Hirschi's theory can occur when using the scale in tests of the theory.

Second, the results indicate that a social bonding measure of self-control is important to understanding digital piracy. That is, the social bonding measure has a negative link with the likelihood to performing digital piracy. Although not examining digital piracy, this result is consistent with Hirschi's (2004) results when he tested this view with a delinquency measure. This result means that individuals are not likely to perform digital piracy because they recognize and feel attached to parents and committed to school. Further, individuals are not likely to perform digital piracy because they see that performing the behavior is likely to reduce the attachments and commitments to school. That is, the attachments and commitments serve as inhibitions that as they increase the probability or likelihood of performing digital piracy reduces providing a form of physical self-restraint. 
Third, the results indicate that the self-generated view of inhibitions from Piquero and Bouffard has a link with digital piracy. Consistent with Hirschi's (2004) view that inhibitions are important in reducing behavior the self-generated inhibitions show that as the individual recognizes and lists more inhibitions then the probability or likelihood of performing digital piracy will decrease. Although not directly examining the link between self-control and digital piracy, this result is consistent with the results from Piquero and Bouffard's (2007) study. This result means that as the individual sees more of their inhibitions then they are less likely to perform digital piracy.

Fourth, the results indicate all three measures of self-control have an important role in understanding the likelihood of performing digital piracy. Specifically, when examined together, all of the measures of self-control have a connection with the likelihood to perform digital piracy. This indicates that the link between self-control and digital piracy is complex. Unlike Piquero and Bouffard (2007) who showed that using their measure reduced the effect of the Grasmick et al. scale, the present study shows that the personality version of self-control and the inhibition versions of self-control are all relevant to understanding digital piracy. The differences between these two studies could be because of the behavior that is being studied. This view suggests that multiple measures of self-control may be necessary to understand behaviors. These results are consistent with Hirschi's (2004) view that his revisions would do little to effect the predictions of the theory.

Overall, these results indicate that different measures are important for understanding digital piracy. The studies on the likelihood of digital piracy have relied on the use of the personality measure of self-control (Higgins 2005, 2006; Higgins and Makin 2004; Higgins et al. 2006). However, the results of the present study indicate that individual differences are important in the determination of the likelihood of digital piracy. Thus, self-control is an important measure in understanding digital piracy.

Although self-control has important implications for understanding digital piracy and not the major focus of the present study, the results indicate that peer association does play a role in digital piracy. Specifically, individuals that seem to associate more with peers that download music are more likely to download music. This interpretation is consistent with Akers (1998) and it is consistent with previous research in digital piracy (Higgins 2005; Higgins et al. 2006).

The present study has implications for policymakers. Specifically, policymakers should consider developing stronger inhibitions toward digital piracy. Based on these findings, this will reduce the instances of digital piracy. Hirschi's (2004) revision would suggest that this approach would help reduce instances of self-control because it will remind the individual of their inhibitions for illegal activity (see Higgins and Wilson 2006 for a more detailed discussion of the educational approach).

While the present study has implications for self-control theory and digital piracy literatures, while providing policy implications, the study has limits. In particular, the study does not examine the implications of digital piracy over time. However, Gottfredson and Hirschi (1990) were clear that cross-sectional studies are fruitful in studying the implications of their theory. Next, the study only examines one specific form of digital piracy. Future researchers should 
examine additional forms of digital piracy. Further, future studies may wish to examine possible interactions among the self-control measures.

Despite the limits of the present study, the results are important. That is, self-control has a link with digital piracy as predicted by Hirschi (2004). Future studies should include longitudinal data and additional measures of digital piracy. For now, the present study indicates that different versions of self-control are important in understanding digital piracy.

\section{NOTES}

${ }^{1}$ Hirschi (2004) argued that his measure does not include a measure of involvement. He goes on to suggest that involvement could be used in this study and other studies.

$* p=.05$.

$* p=.05$.

${ }^{2}$ Following the logic of previous research on self-control associating with criminal peers (Gibson and Wright 2001), moderation tests were performed to determine if self-control interacted with associating with downloading peers. The results show that none of the measures of self-control interact with associating with downloading peers. This could be attributed to the dependent variable. Alternatively, the measures of self-control in the present study are vastly different from the measures of Gibson and Wright (2001).

${ }^{3}$ To test the robustness of the final model, the data were subjected to a simulation study. The simulation study drew its data from a normal distribution in an attempt to recover the findings from model 4. Using 1,000 replications, the simulation study showed little bias in the parameters and standard errors indicating that Type I errors are minimal. Further, the study shows proper levels of statistical power indicating that Type II errors are minimal. Therefore, the model is rather robust.

\section{REFERENCES}

Adler, Peter and Patricia A. Adler. 2006. "The Deviance Society." Deviant Behavior: An Interdisciplinary Journal 27:129-147.

Akers, Ronald L. 1998. Social Learning and Social Structure: A General Theory of Crime and Deviance. Boston, MA: Northeastern University Press.

Bouffard, Jeffrey A. 2002. "Methodological and Theoretical Implications of Using Subject Generated Consequences in Tests of Rational Choice Theory." Justice Quarterly 19:747-771. 
Gibson, Christopher and John P. Wright. 2001. "Low Self-Control and Coworker Delinquency: A Research Note." Journal of Criminal Justice 29:483-492.

Gopal, Ram, Sanders, G. L., Bhattacharjee, S., Agrawal, M., and Wagner, Suzanne. 2004. "A Behavioral Model of Digital Music Piracy." Journal of Organizational Computing and Electronic Commerce 14:89-105.

Gottfredson, Michael R. and Travis Hirschi. 1990. A General Theory of Crime. Stanford, CA: Stanford University Press.

Grasmick, Harold. G., Charles R. Tittle, Robert J. Bursik, and Bruce J. Arneklev. 1993. "Testing the Core Empirical Implications of Gottfredson and Hirschi's General Theory of Crime." Journal of Research on Crime and Delinquency 30:5-29.

Higgins, George E. 2005. "Can Low Self-Control Help With the Understanding of the Software Piracy Problem." Deviant Behavior 26:1-24.

Higgins, George E. 2006. "Gender Differences in Software Piracy: The Mediating Roles of Self-Control Theory and Social Learning Theory." Journal of Economic Crime Management 4:1-22. (www.jecm.org)

Higgins, George E. and David A. Makin. 2004. "Does Social Learning Theory Condition the Effects of Low Self-Control on College Students' Software Piracy?" Journal of Economic Crime Management 2:1-22. (www.jecm.org)

Higgins, George E. and Abby L. Wilson. 2006. "Low Self-Control, Moral Beliefs, and Social Learning Theory in University Students' Intentions to Pirate Software." Security Journal 19:75-93.

Higgins, George E., Brian D. Fell, and Abby L. Wilson. 2006. "Digital Piracy: Assessing the Contributions of an Integrated Self-Control Theory and Social Learning Theory." Criminal Justice Studies: A Critical Journal of Crime, Law, and Society 19:3-22.

Hinduja, Sameer. 2003. "Trends and Patterns Among Online Software Pirates." Ethics and Information Technology 5:49-61.

Hirschi, Travis. 2004. "Self-Control and Crime." In Handbook of SelfRegulation: Research, Theory, and Applications, edited by Roy F. Baumeister and Karen D. Vohs (pp. 537_552).NewYork:Guilford Press. Hirschi, Travis and Michael R. Gottfredson (Eds.). 1994. The Generality of Deviance. New Brunswick, NJ: Transaction.

Hollinger, Richard C. 1988. "Computer Hackers Follow a Guttman-Like Progression." Sociology and Social Research 72:199-200. 
Husted, Bryan W. 2000. "The Impact of National Culture on Software Piracy." Journal of Business Ethics 13:431-438.

Im, Jim H. and Clifford Koen. 1990. "Software Piracy and Responsibilities of Educational Institutions." Information and Management 18:189-194.

International Federation of Phonographic Industries (IFPI). 2006. "The Recording Industry 2006 Piracy Report: Protecting Creativity in Music." Retrieved on October 16, 2007, from http://www.ifpi.org Muthen, Linda, K. and Bengt O. Muthen. 2002. "How to Use a Monte Carlo Study to Decide on Sample Size and Determine Power." Structural Equation Modeling 9:599-620.

Piquero, Alex R. and Jeff Bouffard. 2007. "Something Old, Something New: A Preliminary Investigation of Hirschi's Redefined SelfControl." Justice Quarterly 24:1-27.

Piquero, Alex R. and Stephen Tibbetts. 1996. "Specifying the Direct and Indirect Effects of Low Self-Control and Situational Factors in Offenders' Decision Making: Toward a MoreComplete Model of Rational Offending." Justice Quarterly 13:481-510.

Pratt, Travis C. and Francis T. Cullen. 2000. "The Empirical Status of Gottfredson and Hirschi's General Theory of Crime: A Meta-Analysis." Criminology 38:931-964.

Tittle, Charles, David A. Ward, and Harold Grasmick. 2003.

"Self-Control and Crime=Deviance: Cognitive vs. Behavioral Measures." Journal of Quantitative Criminology 19:333-365.

Wall, David S. (2005). "The Internet as a Conduit for Criminal Activity." Pp. 78_94. In Information Technology and the Criminal Justice System, edited by A. Pattavina. Thousand Oaks, CA: Sage Publications. 